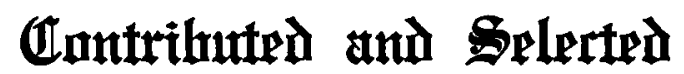

\section{ASH AND MOISTURE CONSTANTS OF POWDERED VEGETABLE DRUGS.}

AZOR THLRSTON AND A. N. THURSTON, GRAND RAPIDS, OHIO.

Some time ago we published ${ }^{1}$ an article under the above title. The results reported were obtained by analysis of commercial samples.

The great variation in the ash of a number of the powders lead us to believe that this line of drugs was grossly adulterated, therefore we ordered from two well known drug millers samples of the best grade of their products. They were informed for what purpose we wanted the drugs and no doubt they furnished as near pure articles as were obtainable. The wide variation as shown by the results of analysis would certainly indicate that even the best obtainable drugs will vary greatly.

Determinations as here reported are as follows-moisture, ash, water soluble ash, water insoluble ash, alkalinity of water soluble ash and alkalinity of water insoluble ash.

In every case exactly 2 grams of the sample were used for the determinations. The amount reported as water or moisture includes all the volatile portion at $100^{\circ} \mathrm{C}$. The ash was obtained by incinerating the dried solids. In case of incomplete combustion of the carbon a few drops of water was added to the ash and evaporated to dryness on a water bath, then again brought to a red heat. This treatment worked fully as well as the customary method of "leaching out" and with less chance of error.

The alkalinity of ash is represented as the number of cubic centimeters of decinormal acid required to neutralize the ash from one gram of the sample Methyl orange being used as indicator.

With one exception the drugs reported are official in the U. S. P. VIII. Belladonna Leaves is the only one that has U. S. P. official ash standard and the samples analyzed gave 12.78 and 14.43 percent ash which comes well within the standard of 15 . Hydrastis gave 5.44 and 10.99 percent ash while four ${ }^{2}$ foreign pharmacopoias have a standard of 6 percent ash.

${ }^{2}$ Proceedings Ohio State Pharmaceutical Association, 1911, page 69.

'Jr. A. Ph. A., Vol. I, page 457. 


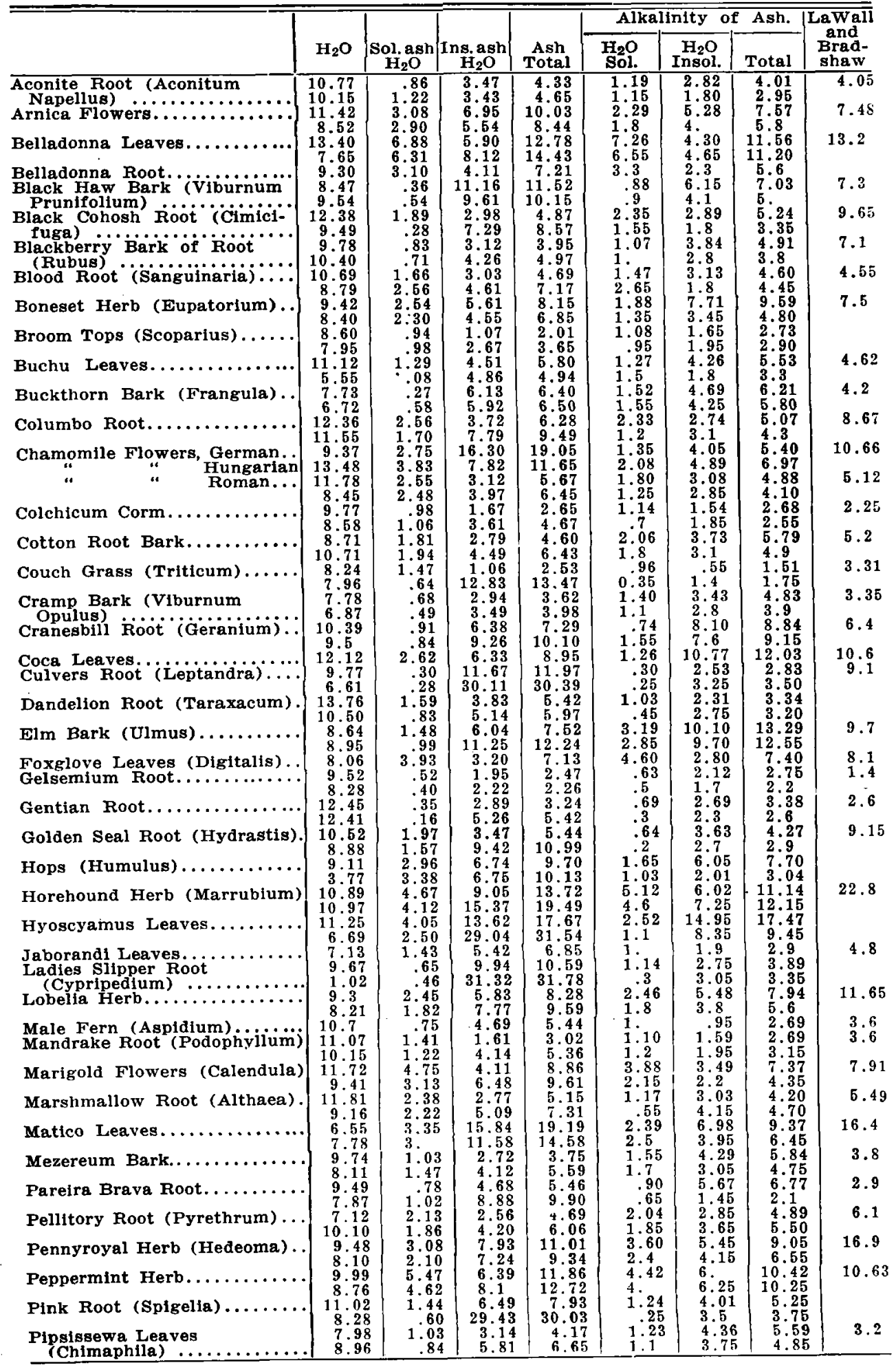




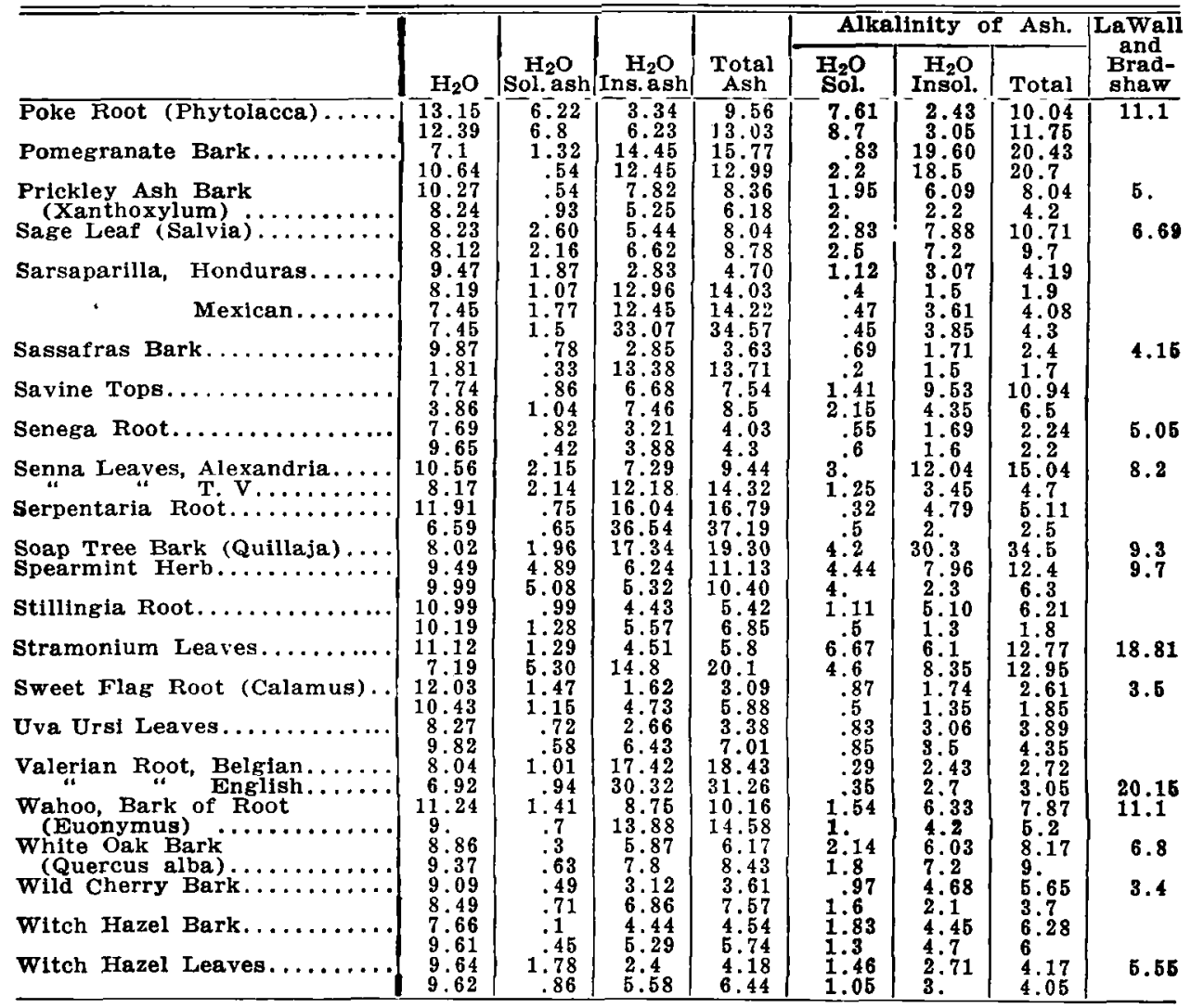

For comparison we have given in column eight the average ash of samples as determined by LaWall \& Bradshaw. ${ }^{3}$

Lloyd ${ }^{4}$ in his classical work on hydrastis does not mention an ash standard. The ash as a standard of itself should not be considered in case of alkaloidal drugs like hydrastis, but it is of sufficient importance to add another constant when adulterations are so prevalent.

\section{THE DISPENSING OF OILY SUBSTANCES.*}

\section{J. LEON LASCOFF, NEW YORK.}

In presenting this subject to you I have borne in mind the fact that prescriptions submitted to us with oily substances are difficult to dispense in a form which shall be both elegant in appearance and have uniform distribution. I refer especially to mineral oils.

Oils of the hydrocarbon variety are not easily miscible with some ingredients: firstly, their tendency when standing is to separate themselves; secondly,

'Proceedings A. Ph. A., 1910, Vol. 58, pages 750-755.

'Lloyd's Drugs and Medicines, pages 76-184.

* Read before the Kings County Pharmaceutical Society, March 11, 1912. 